\title{
Initial Phylotranscriptomic Confirmation of Homoplastic Evolution of the Conspicuous Coloration and Bufoniform Morphology of Pumpkin-Toadlets in the Genus Brachycephalus
}

\author{
Mariana L. Lyra ${ }^{1,+}{ }^{+}$Juliane P. C. Monteiro ${ }^{1,+}{ }^{+}$, Loïs Rancilhac $^{2}$, Iker Irisarri ${ }^{3}{ }^{(0}$, Sven Künzel ${ }^{4}$, \\ Eugenia Sanchez $^{2}{ }^{\mathbb{D}}$, Thais H. Condez ${ }^{5}{ }^{(0}$, Omar Rojas-Padilla $^{6}$, Mirco Solé $\left.^{7}{ }^{(}\right)$, Luís Felipe Toledo ${ }^{8}$, \\ Célio F. B. Haddad ${ }^{1}$ and Miguel Vences ${ }^{2, *}$ (])
}

1 Instituto de Biociências, Departamento de Biodiversidade (Campus Rio Claro), Universidade Estadual Paulista (UNESP), Avenida 24A, N 1515, Bela Vista, Rio Claro 13506-900, SP, Brazil; marillyra@gmail.com (M.L.L.); julianepmonteiro@gmail.com (J.P.C.M.); haddad1000@gmail.com (C.F.B.H.)

2 Zoological Institute, Technische Universität Braunschweig, 38106 Braunschweig, Germany; loisrancilhac@gmail.com (L.R.); eu.sanisa@gmail.com (E.S.)

3 Institute for Microbiology and Genetics, Department of Applied Bioinformatics, University of Goettingen, Goldschmidtstr, 1, 37077 Göttingen, Germany; irisarri.iker@gmail.com

4 Max Planck Institute for Evolutionary Biology, 24306 Plön, Germany; kuenzel@evolbio.mpg.de

5 Unidade Passos, Universidade do Estado de Minas Gerais (UEMG), Avenida Juca Stockler 1130, Passos 37900-106, MG, Brazil; thacondez@gmail.com

6 Laboratório de Sistemática de Vertebrados, Pontifícia Universidade Católica do Rio Grande do Sul, Av. Ipiranga 6681, Porto Alegre 90619-900, RS, Brazil; projasomar@gmail.com

updates

Citation: Lyra, M.L.; Monteiro, J.P.C.; Rancilhac, L.; Irisarri, I.; Künzel, S.; Sanchez, E.; Condez, T.H.; Rojas -Padilla, O.; Solé, M.; Toledo, L.F.; et al. Initial Phylotranscriptomic Confirmation of Homoplastic Evolution of the Conspicuous Coloration and Bufoniform Morphology of Pumpkin-Toadlets in the Genus Brachycephalus. Toxins 2021, 13, 816. https://doi.org/10.3390/ toxins 13110816

Received: 3 September 2021 Accepted: 15 November 2021 Published: 19 November 2021

Publisher's Note: MDPI stays neutral with regard to jurisdictional claims in published maps and institutional affiliations.

Copyright: (C) 2021 by the authors. Licensee MDPI, Basel, Switzerland. This article is an open access article distributed under the terms and conditions of the Creative Commons Attribution (CC BY) license (https:// creativecommons.org/licenses/by/ $4.0 /)$.
7 Departamento de Ciências Biológicas, Universidade Estadual de Santa Cruz, Ilhéus 45662-900, BA, Brazil; mksole@uesc.br

8 Laboratório de História Natural de Anfíbios Brasileiros (LaHNAB), Departamento de Biologia Animal, Instituto de Biologia, Universidade Estadual de Campinas, Campinas 13083-862, SP, Brazil; toledosapo@gmail.com

* Correspondence: m.vences@tu-braunschweig.de; Tel.: +49-531-391-3237

+ These authors contributed equally to this study.

Abstract: The genus Brachycephalus is a fascinating group of miniaturized anurans from the Brazilian Atlantic Forest, comprising the conspicuous, brightly colored pumpkin-toadlets and the cryptic flea-toads. Pumpkin-toadlets are known to contain tetrodotoxins and therefore, their bright colors may perform an aposematic function. Previous studies based on a limited number of mitochondrial and nuclear-encoded markers supported the existence of two clades containing species of pumpkin-toadlet phenotype, but deep nodes remained largely unresolved or conflicting between data sets. We use new RNAseq data of 17 individuals from nine Brachycephalus species to infer their evolutionary relationships from a phylogenomic perspective. Analyses of almost 5300 nuclearencoded ortholog protein-coding genes and full mitochondrial genomes confirmed the existence of two separate pumpkin-toadlet clades, suggesting the convergent evolution (or multiple reversals) of the bufoniform morphology, conspicuous coloration, and probably toxicity. In addition, the study of the mitochondrial gene order revealed that three species (B. hermogenesi, B. pitanga, and B. rotenbergae) display translocations of different tRNAs (NCY and CYA) from the WANCY tRNA cluster to a position between the genes ATP6 and COIII, showing a new mitochondrial gene order arrangement for vertebrates. The newly clarified phylogeny suggests that Brachycephalus has the potential to become a promising model taxon to understand the evolution of coloration, body plan and toxicity. Given that toxicity information is available for only few species of Brachycephalus, without data for any flea-toad species, we also emphasize the need for a wider screening of toxicity across species, together with more in-depth functional and ecological study of their phenotypes.

Keywords: Amphibia; Anura; RNAseq; phylogenomics; mitochondrial genomes; mitochondrial gene order; convergence; aposematism 
Key Contribution: A phylogenomic analysis based on over 5000 nuclear-encoded markers suggests that the bright-colored and toxic pumpkin-toad phenotype may have evolved convergently twice.

\section{Introduction}

The evolution of aposematism, i.e the co-occurrence of conspicuous coloration and defensive mechanisms, is fascinating and poorly understood, despite intensive research over many decades (e.g., [1-5]). Whether an apparently bright and conspicuous colour pattern is aposematic (i.e., it has primarily a warning function) rather than serving intraspecific communication or even camouflage [1,6,7] and how warning colour integrates with the evolution of other phenotypic characters [8] are intriguing questions that can only be answered by subjecting a variety of animal systems to experimental (e.g., [9-11], phylogenetic (e.g., [12]), and genomic research (e.g., [13]).

Amphibians have long been a prime group for research on the evolution of aposematism and contain a large number of species that exhibit putative warning signals [14]. They are also the only class of terrestrial vertebrates known to contain tetrodotoxin analogues (TTX; [15]). One example is the Brazilian genus Brachycephalus which currently comprises 38 described species [16], all endemic to the Atlantic Forest biome between $15^{\circ}$ and $26^{\circ}$ latitude from sea level up to $2000 \mathrm{~m}$ [17] (Figure 1). Species in this genus are essentially diurnal, leaf-litter inhabitants, miniaturized, and characterized by direct development $[18,19]$. Brachycephalus species are divided into two groups according to their body plans, popularly known as pumpkin-toadlets (34 species) and flea-toads (4 species) [20]. All pumpkin-toadlets are characterized by a "bufoniform" appearance, with a robust body and pectoral girdle, head as wide as long and short snout; the flea-toads instead have a "leptodactyliform" appearance with slender body and pectoral girdle, head longer than wide and long snout (Supplementary Figure S1). The relatively more elongated skull of the flea-toads is also reflected in a skeletal multivariate morphospace [20]. The coloration of pumpkin-toadlets is usually bright, orange/yellow but sometimes greenish/brownish dorsally, and always with some orange components at least on the hands and feet and/or on the ventral surface. Several pumpkin-toadlets are also known to contain toxins: TTX has been reported in B. ephippium, B. nodoterga, B. pernix, B. pitanga, and B. rotenbergae (as B. ephippium) $[15,21,22]$ and bradykinin-potentiating peptides (BPP) have been reported in B. rotenbergae ([23] —as B. ephippium). On the contrary, flea-toads have an inconspicuous brown coloration $[19,20]$ and their putative toxicity has so far not been assessed. These characteristics make Brachycephalus an excellent model for studying the evolution of anti-predator defense mechanisms associated with toxins.

Surprisingly, early molecular phylogenetic evidence (Figure 2A) suggested that these two morphological groups are not reciprocally monophyletic within Brachycephalus [18]. Based on DNA sequences of few mitochondrial and two nuclear-encoded genes (tyrosinase and recombination activating gene 1), two major clades of pumpkin-toadlets were recovered: the B. ephippium group (with 15 species), characterized by a gradient of increased mineralization in the skull [20,24-27], and the B. pernix group (with 19 species), which is not hyperossified [18-20]. The B. ephippium group is distributed across the Serra do Mar and Serra da Mantiqueira mountain ranges whereas the B. pernix group is distributed across the Serra do Mar, respectively at the north and south of the Guapiara Lineament [19] (Figure 1). However, the relationships of the flea-toad species within Brachycephalus (B. didactylus, B. hermogenesi, B. pulex, and B. sulfuratus) remain incompletely resolved (Figure 2). Mitochondrial analyses recovered B. didactylus sister to the B. ephippium group with high support, as well as $B$. sulfuratus sister to the B. pernix group $[19,20]$. Brachycephalus hermogenesi was recovered either nested within the B. ephippium group [18] or sister to a clade encompassing all other Brachycephalus with low support [19]. The northernmost distributed species B. pulex (Figure 1) seems to split from a deep node in the Brachycephalus tree [20], how- 
ever, the relationship between this species and other Brachycephalus spp. are not well supported $[19,20]$.

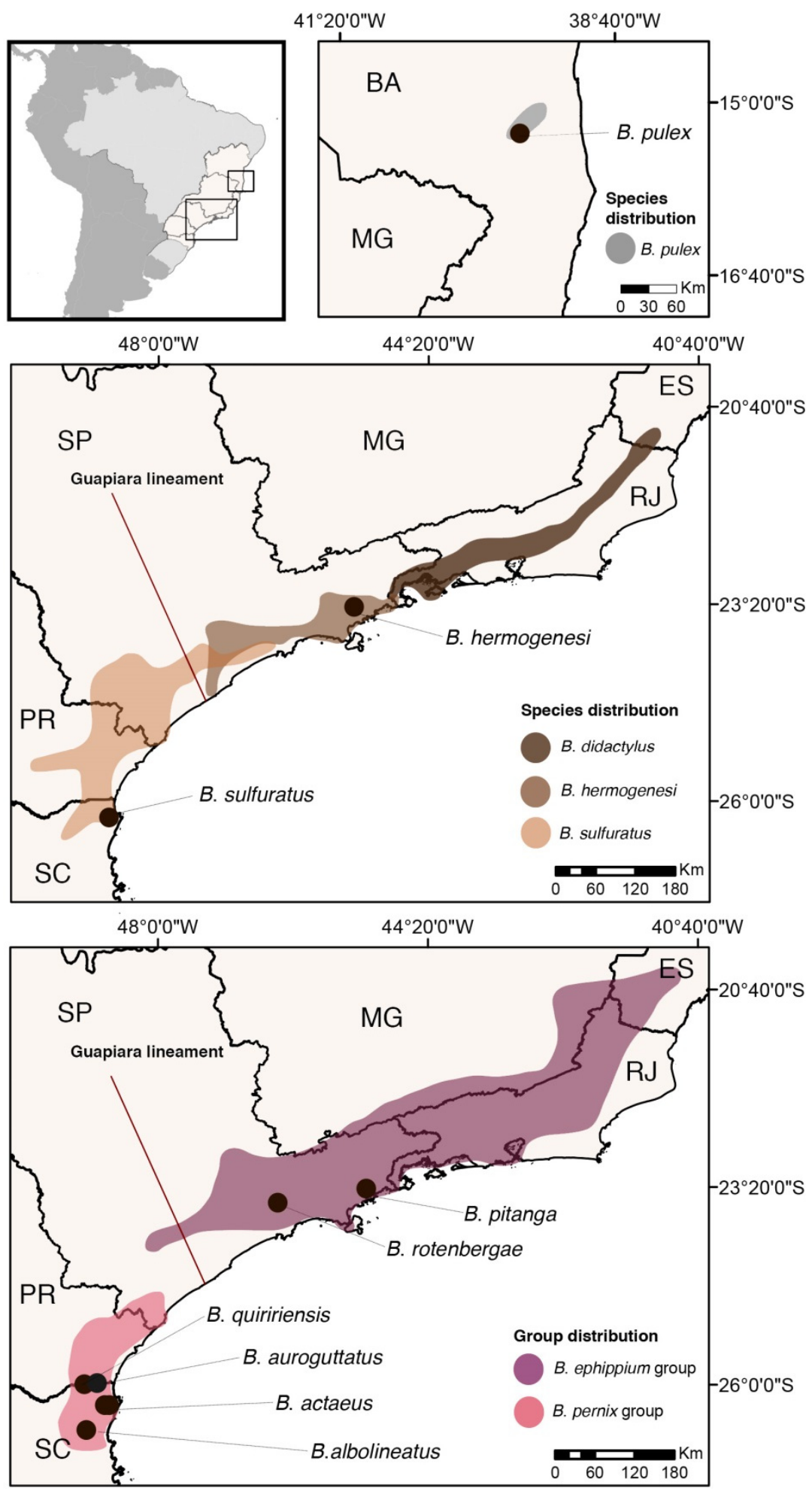

Figure 1. Approximate distribution map for genus Brachycephalus based on literature records, with sampling localities for each species included in the phylogenomic analysis. Acronyms for Brazilian states: BA, Bahia; ES, Espírito Santo; MG, Minas Gerais; PR, Paraná; RJ, Rio de Janeiro; SC, Santa Catarina; and SP, São Paulo. 


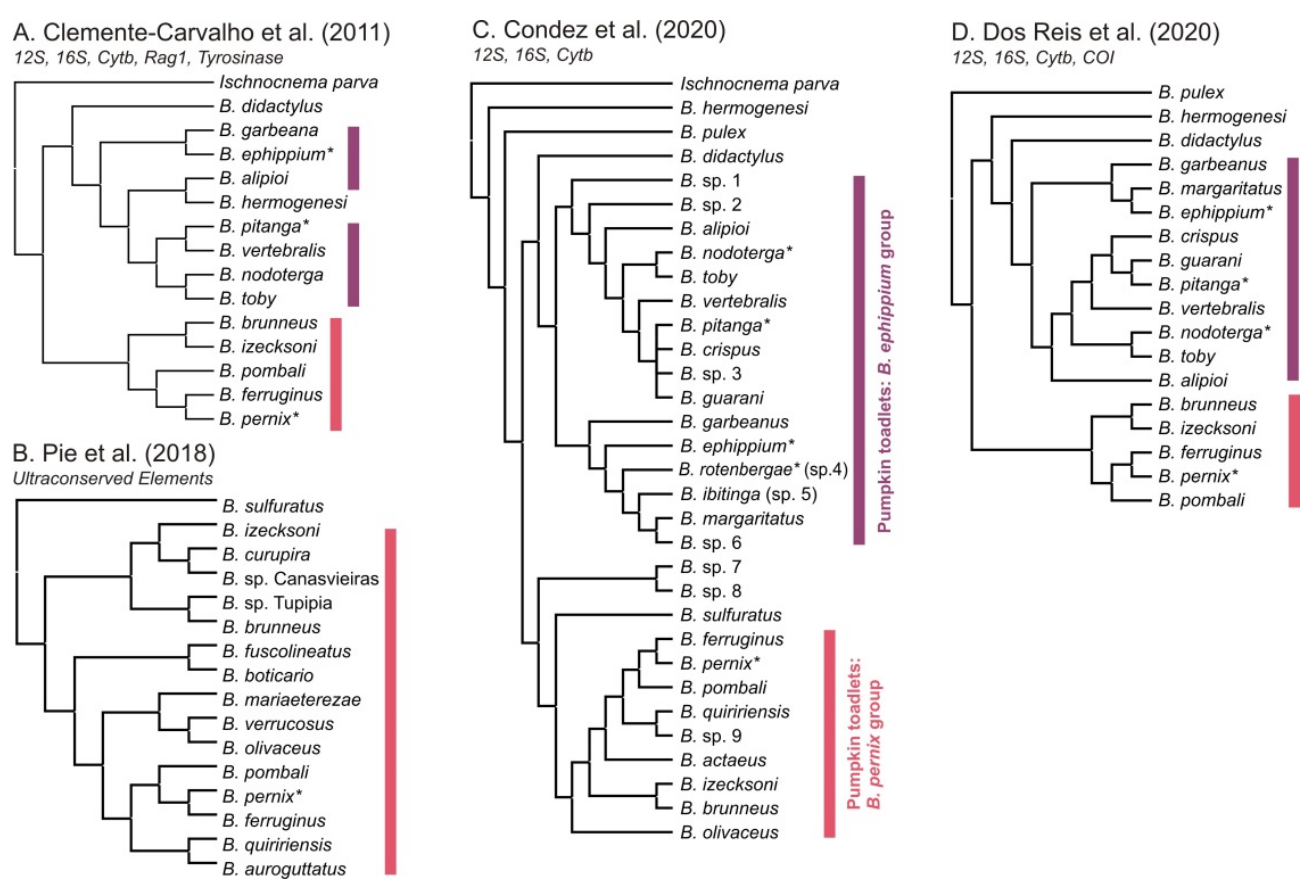

Figure 2. Summary of selected results from previous phylogenetic analyses of the genus Brachycephalus: (A) Bayesian inference (BI) analysis of a concatenated matrix $4563 \mathrm{bp}$ of three mitochondrial and two nuclear gene fragments [18]; (B) BI analysis of 155,683 bp of 303 concatenated ultraconserved (UCE) loci [28]; (C) BI analysis of 2372 bp of three concatenated mitochondrial gene fragments [19] (D) species tree estimation from 4826 bp of four mitochondrial gene fragments [20]. Purple bars refer to the B. ephippium group and pink bars refers to the B. pernix group. Asterisks $\left(^{*}\right)$ mark species known to contain toxins (TTX). The two groups of pumpkin-toadlets are marked with vertical bars; other species are flea-toads (or outgroup: Ischnocnema). Note that B. rotenbergae has only recently been recognized as a distinct species and some sequences as well as toxin data assigned to B. ephippium in earlier studies may refer to this species.

Although current knowledge suggests homoplasy of the aposematic coloration and body plan in pumpkin-toadlets, the conflicting and often poorly supported phylogenetic placements of various flea-toad species do not allow understanding whether the multiple instances of the pumpkin-toadlet phenotype represents homoplasy or shared ancestry. Here, we aim to assess the relationships within Brachycephalus with new phylogenomic data derived from RNAseq from representatives of each major clade of pumpkin-toadlets and three species of flea-toads, thus representing most of the main clades within the genus. We analyzed complete mitochondrial genomes reconstructed from the RNAseq data as well as a comprehensive phylotranscriptomic data set of over 5000 nuclear-encoded protein-coding genes, which resulted in largely congruent and supported hypotheses for the evolutionary history of Brachycephalus.

\section{Results}

\subsection{Phylogenetic Relationships}

The final phylotranscriptomic dataset consisted of 5296 alignments of ortholog nuclearencoded protein-coding genes, totaling 7,612,827 aligned nucleotide positions. Partitioned ML analysis of the concatenated data set resulted in a fully resolved tree (Figure 3A) with full support on all internal branches, except for two intraspecific nodes connecting individuals of $B$. rotenbergae. The ASTRAL tree recovered the same topology with fully supported inter-specific relationships as well (Supplementary Figure S2). The ML analysis of the concatenated alignment of 13,938 mitochondrial nucleotide positions (the two rRNA and the 13 protein-coding genes) yielded a tree overall concordant to that obtained from the nuclear-encoded data (Figure 3B; Supplementary Figure S3), the disagreements affecting deep nodes that were poorly resolved by the mitogenomic data and the position of one species within the B. pernix group (B. albolineatus, see below). 
A RNAseq: 5296 loci, 7.6 million nt

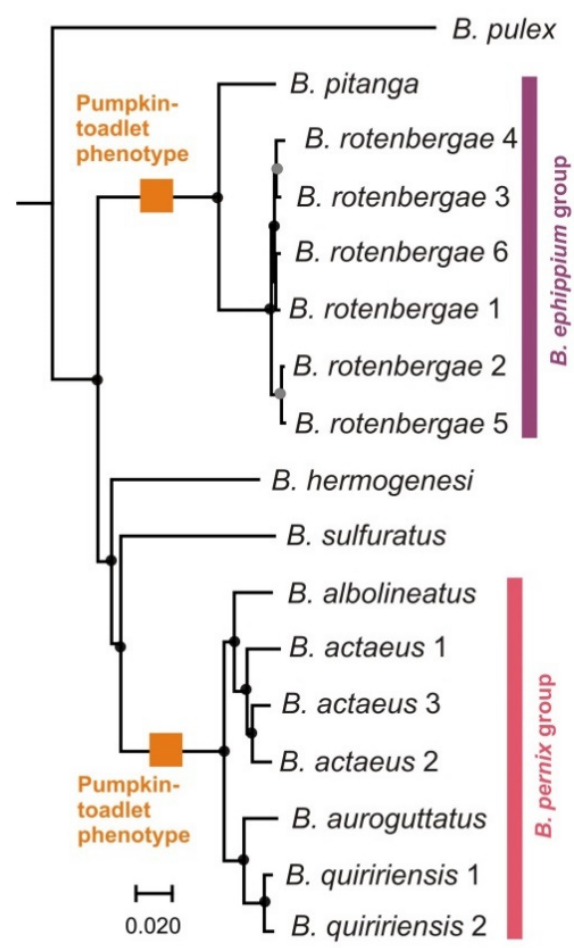

B mt genomes: $13938 \mathrm{nt}$

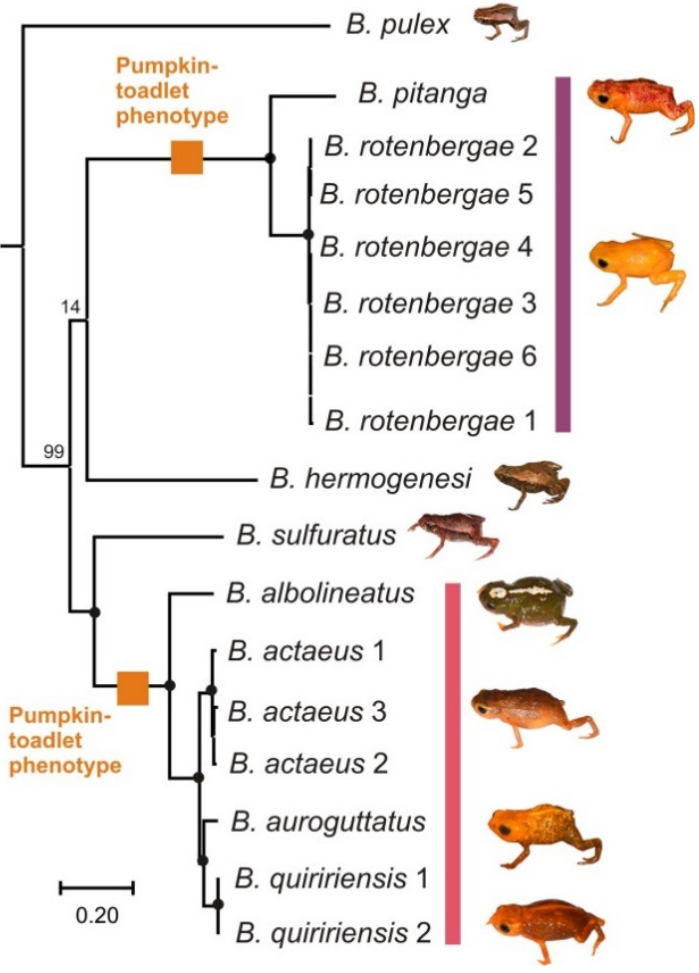

Figure 3. Phylogenomic trees of Brachycephalus spp. (A) Maximum Likelihood (ML) tree calculated from a concatenated alignment of 7,612,827 nucleotide positions (nt) of 5296 nuclear-encoded protein-coding markers derived from transcriptomes. Black circles at nodes indicate full support from both the analysis of the concatenated dataset (with IQTREE: 100\% for 1000 aLRT pseudoreplicates) and from a species tree analysis (with ASTRAL: 1.0 local posterior probability); grey nodes received $100 \%$ support in the IQTREE analysis but a posterior probability $<1.0$ in the ASTRAL analysis. (B) Maximum likelihood tree calculated from a concatenated alignment of 13,938 nucleotide positions of the two rRNA genes and the 13 protein coding genes from full mitochondrial genomes. Black circles at nodes indicate $100 \%$ bootstrap support, other bootstrap values are written out (except for the most shallow intraspecific nodes). Orange squares mark clades composed of species characterized by the pumpkin-toadlet phenotype (bufoniform morphology, conspicuous orange coloration at least on some parts of the body, and probable toxicity), as opposed to the flea-toad phenotype (leptodactyliform morphology, cryptic coloration and possibly reduced toxicity) of B. pulex, B. hermogenesi and B. sulfuratus. Both trees were rooted with Ischnocnema henselii as outgroup (removed from the figure for better graphical representation of the trees). Scale bars represent expected substitutions per site.

The two data sets are concordant regarding the phylogenetic relationships of the fleatoads B. pulex and B. sulfuratus. Brachycephalus pulex is placed sister to all other included Brachycephalus with full support (100\% aLRT in the nuclear tree, $99 \%$ bootstrap support in the mitochondrial tree; Figure 3). Brachycephalus sulfuratus is placed with maximum support in all analyses as sister to one clade of pumpkin-toadlets (the B. pernix group). The analyses also recovered the included species of the B. ephippium group, and of the B. pernix group, as monophyletic, respectively. The phylogenetic position of the flea-toad $B$. hermogenesi was contradictory. Whereas the phylotranscriptomic analyses recovered it sister to the clade containing the B. pernix group and B. sulfuratus with maximum support, the mitogenomic analysis placed it as sister to the B. ephippium group but without support (bootstrap proportion $=14 \%$ ). The position of B. albolineatus within the B. pernix group was also different between the datasets: phylotranscriptomic analyses recovered the species as sister to B. actaeus, whereas the mitogenomic analysis placed it sister to the B. pernix group. These alternative topologies received maximum support by the analyses of the respective data sets. All species covered by multiple samples were monophyletic with high support and displayed short intra-specific branches. 


\subsection{Reconstruction of Phenotype Evolution}

Reconstruction of ancestral character states via Bayesian stochastic character mapping yielded ambiguous results where most deep nodes in the tree had similar probabilities for both phenotypes (Figure 4), with a tendency of higher probabilities for bright color and bufoniform body plan. Similar results were found when the outgroup (Ischnocnema) was either included or excluded. An explorative parsimony analysis (Fitch optimization in TNT; [29]) reconstructed a convergent evolution of the pumpkin-toadlet phenotype, i.e., according to this approach, both the bufoniform body plan and bright coloration originated independently in the B. ephippium and the B. pernix group (Supplementary Figure S4).

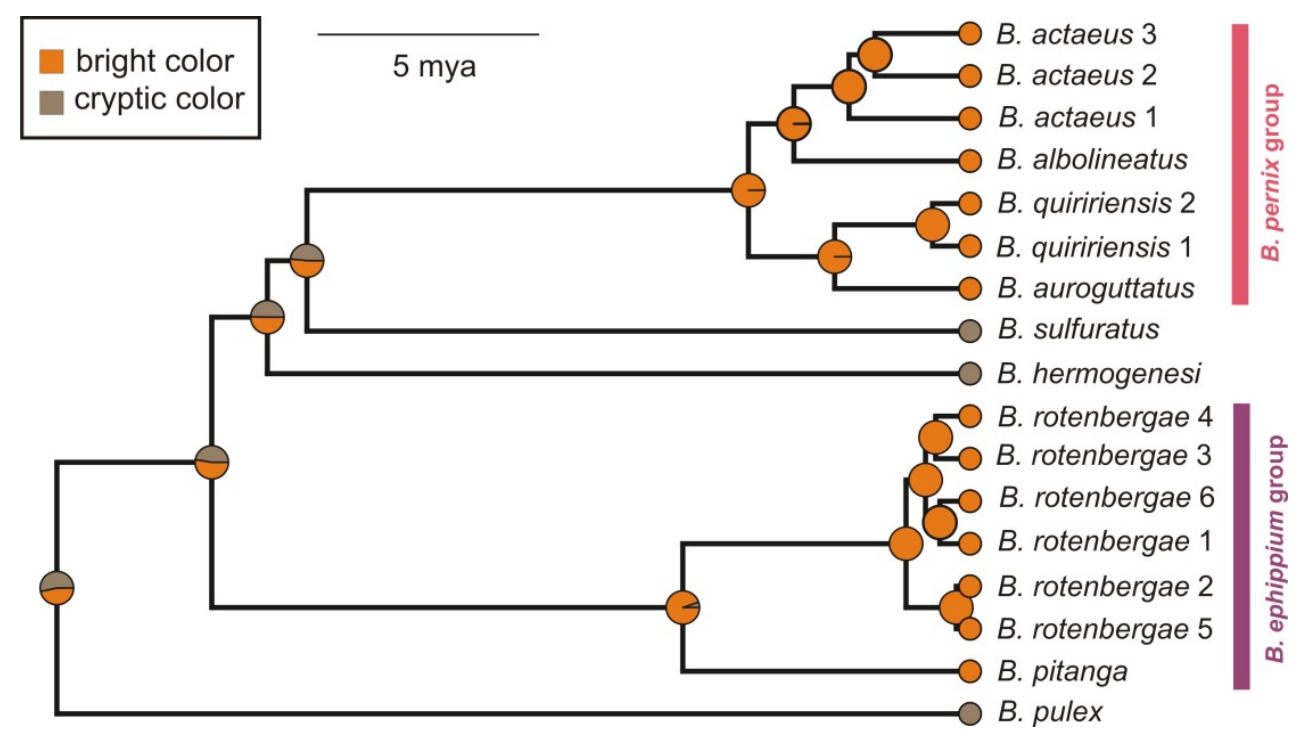

Figure 4. Brachycephalus phenotype reconstructed under a Bayesian (stochastic character mapping; SIMMAP) using phytools. Identical reconstructions were obtained for color (shown), and for bufoniform vs. leptodactyliform morphology. The character state "bright color" defines species that have at least some part of the body surface colored bright orange (dorsum, hands and feet, or ventral surface). Scale bar represents 5 million years it is based on calibration of the Ischnocnema/Brachycephalus split at 35 million years ago (see methods).

\subsection{Mitogenome Gene Order}

Near-complete mitogenomes were recovered for all specimens, including the two ribosomal genes (12S and $16 \mathrm{~S}$ rRNA), the 13 protein-coding genes, and most tRNAs (Figure 5). We also recovered partial control region (CR) sequences for B. pitanga and I. henselii. Most genes are transcribed from the H-strand, except for ND6 and eight tRNA genes, as known for other anurans [30,31]. We found only a few regions with low coverage in all mitogenomes, mostly representing partial tRNA regions and the $3^{\prime}$ or $5^{\prime}$ regions of coding-sequences. This pattern is expected when by-catching mitogenomes from RNAseq data.

The gene arrangement in B. pulex, B. sulfuratus and species of the B. pernix group follows the most common order known for Neobatrachia [31,32] (Figure 5A). However, two novel tRNA gene rearrangements were found for B. hermogenesi and for B. pitanga + $B$. rotenbergae. In these three species genes from the WANCY tRNA cluster are rearranged to the region between ATP6 and COIII. In B. hermogenesi the tRNAs N, C, and Y are translocated, probably in a single translocation event maintaining the same order found in the WANCY cluster (Figure 5B). In B. pitanga and B. rotenbergae, instead, the tRNAs $\mathrm{A}, \mathrm{C}$, and $\mathrm{Y}$ were found in between ATP6 and COIII, and furthermore the tRNA-A was found after tRNAs $C$ and $Y$ (Figure $5 C$ ). These new arrangements did not affect the position of the origin of replication for the light-strand synthesis $\left(\mathrm{O}_{\mathrm{L}}\right)$ (Figure 5). Strikingly, the other species of Brachycephalus also have a non-coding region between ATP6 and COIII, which is missing in the outgroup (Ischnocnema). Given the high coverage and quality of 
the fragment spanning between ATP6 and COIII in most assemblies, these arrangements are unlikely to be artefactual. In addition, the de novo assembly using the program mitoZ also recovered these arrangements, and PCR tests confirmed different length fragments for species of rearranged gene order vs. standard gene order (Supplementary Figure S5).

A: Standard mitochondrial gene order in Neobatrachia

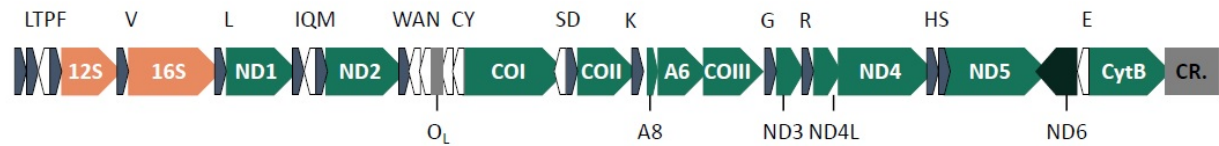

B: Brachycephalus hermogenesi

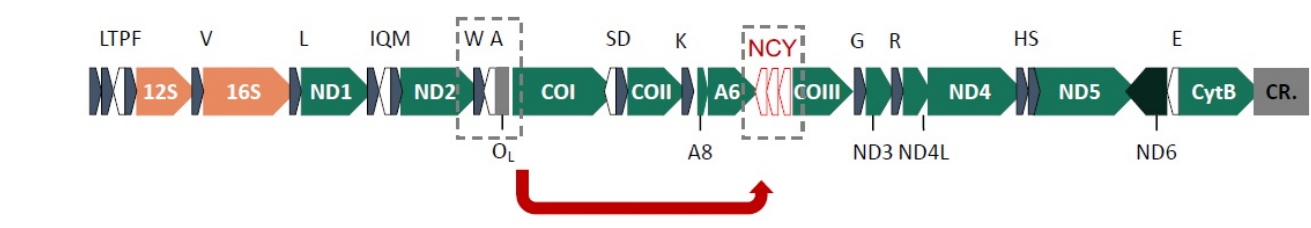

C: Brachycephalus rotenbergae / Brachycephalus pitanga

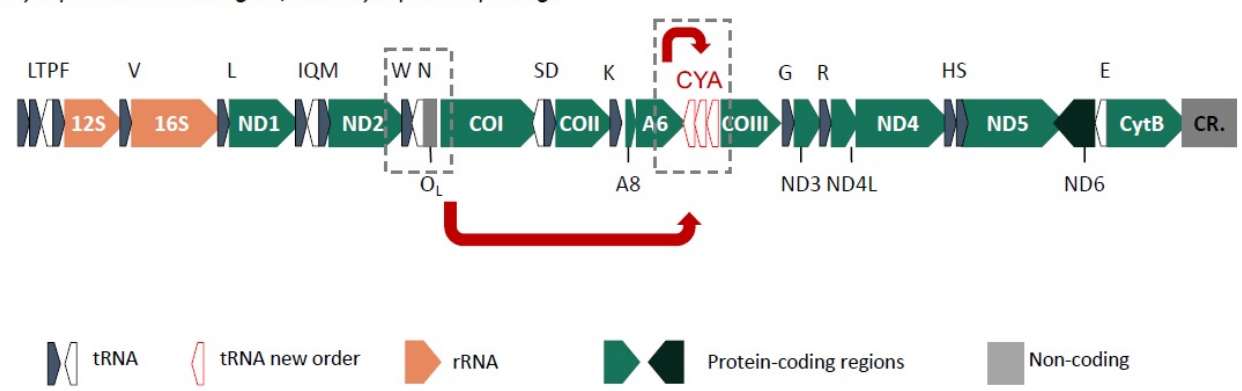

Figure 5. Schematic representation of mitochondrial DNA gene arrangement in Brachycephalus. Arrows represent rearrangements in relation to standard gene order of Neobatrachia. The black squares highlight the rearrangement region. Gene alias follows HUGO gene nomenclature committee (https:/ / www.genenames.org/; accessed on 1 September 2021). (A) Standard mitochondrial gene order as observed in most Neobatrachia; (B) gene order observed in B. hermogenesi; (C) gene order observed in B. rotenbergae and B. pitanga.

\section{Discussion}

\subsection{Evolution and Biogeography of Brachycephalus}

The phylotranscriptomic and mitogenomic analyses conducted herein support that flea-toads do not represent a monophyletic group exclusive of pumpkin-toadlets. The analyses recovered B. pulex as the sister species to all other Brachycephalus with high support, as previously suggested [20]. The position of B. sulfuratus, sister to the B. pernix group, also agrees with previous studies based on mitochondrial DNA markers $[19,20]$. The phylogenetic position of $B$. hermogenesi was not unambigously solved by the analyses herein; the phylotranscriptomic dataset suggests a novel phylogenetic relationship of this species not recovered by previous studies, being the sister clade of B. sulfuratus + B. pernix group, whereas its position remained poorly supported in the mitogenomic tree. A single species of flea-toad, B. didactylus, is missing from our phylogenomic analyses. However, in all previous works, this taxon was consistently recovered with high support as sister to the B. ephippium group [18-20] and this position was also recovered in an analysis including these data along with our mitogenomic sequences (Supplementary Figure S6). Therefore, we expect this position will also be confirmed once phylogenomic data for this species become available.

Our results corroborate previous analyses in recovering two fully supported clades of conspicuous pumpkin-toadlets: (i) the B. ephippium group (represented by B. pitanga and B. rotenbergae), and (ii) the B. pernix group (represented by B. actaeus, B. albolineatus, B. auroguttatus, and B. quiririensis) [18-20]. As far as known, in Brachycephalus the pumpkin- 
toadlet phenotype includes two components that in all known species are linked (bufoniform morphology and conspicuous coloration), i.e., all bufoniform species of the genus are also more or less brightly colored (sometimes including green and brownish morphs). Stochastic character mapping could not reliably reconstruct the ancestral phenotype of Brachycephalus and the polarization of character states therefore remains ambiguous (Figure 4). The pumpkin-toadlet phenotype can be hypothesized to be derived given its absence in Ischnocnema, the sister clade of Brachycephalus, and along with other studies [20] we consider the hypothesis of convergent origin of this derived phenotype more likely, rather than postulating multiple reversals. We anticipate that this hypothesis will receive stronger support if the probable sister-group relationship of the B. ephippium clade and the flea-toadlet B. didactylus $[19,20]$ (Supplementary Figure S6 herein) is confirmed by future phylogenomic data sets and included in the ancestral character state reconstruction, but at present it is clear that the details of the phenotype homoplasy in Brachycephalus cannot be resolved with full reliability.

Furthermore, the two pumpkin-toadlet clades show different patterns of ossification. In the B. ephippium group, species have remarkably ossified skulls and vertebral columns, sometimes with a bony dorsal shield, and bone sculpturing consisting of ridges and crests inducing a reticulated or pitted pattern in the skull, spinal processes of sacral, and presacral vertebrae $[20,25]$. In contrast, in the $B$. pernix group, such hyper-ossification is not observed $[19,20,27]$. This might indicate that the bufoniform appearance of these toadlets is ontogenetically based on different developmental processes, which would be in agreement with an independent evolutionary origin.

From a biogeographical perspective, a previous study [19] hypothesized that the ancestral distribution of Brachycephalus was in the northern part of its current range, specifically in high-elevation regions in the northern Serra do Mar mountain range. From the results obtained herein, we can refine this hypothesis relying on the assumptions that (i) our phylotranscriptomic tree correctly represents the evolutionary history of the main Brachycephalus clades, and (ii) the phylogenetic position of the flea-toad species B. didactylus has been correctly recovered by previous studies (see also Supplementary Figure S6). The flea-toad B. pulex was recovered sister to all other Brachycephalus spp. and occupies the northernmost distribution range (Figure 1). Hence, it is possible that the initial split in the genus occurred between a northern and central/southern ancestral Atlantic Forest species, both likely possessing a flea-toad morphology. In this hypothesis, the subsequent split may have separated two main further clades characterized by an ancestral flea-toad phenotype. One of these occupied much of the central part of the Atlantic Forest, with a widespread species of flea-toad morphology (B. didactylus) and one clade, the B. ephippium group, evolving the pumpkin-toadlet phenotype (Figure 1). The second clade would have dispersed southwards where successive stages of this colonization are represented by the flea-toad lineages, B. hermogenesi and B. sulfuratus, and the B. pernix group that evolved the pumpkin-toadlet phenotype (Figure 1).

\subsection{Mitogenome Evolution and Cyto-Nuclear Discordance}

Gene rearrangements comparable to those observed in Brachycephalus have been reported in all lissamphibian orders [30,33-35]. Especially the WANCY genomic region has been previously considered a hotspot for gene order rearrangements [33,34]. For example, the caecilians Luetkenotyphlus brasiliensis and some Siphonops spp. have different arrangements for tRNAs in this region (NCYWA and ACWNY, respectively) [34]. However, the partial rearrangement of some of these tRNA genes to the position between the ATP6 and COIII genes, as observed in several Brachycephalus, is new for vertebrates.

The mitochondrial gene order could be interpreted as supporting a close relationship of B. hermogenesi and the B. ephippium group, given that in both, genes from the WANCY tRNA cluster were translocated to the region between ATP6 and COIII, an unprecedented position for such translocations among frogs. However, since different tRNAs were affected by this translocation in these taxa, and furthermore in a different order, it is unlikely that 
the observed pattern reflects a single, ancestral translocation event. It is more likely that a complex history of multiple translocations and maybe translocation reversals affected the mitochonodrial genomes of Brachycephalus species, as supported by the presence of noncoding DNA at this position in all species studied, including the earliest diverging lineage, $B$. pulex. It also cannot be fully ruled out that the shared position of the translocated tRNA clusters in B. hermogenesi and the B. ephippium group might be due to an early mitochondrial introgression event among ancestral Brachycephalus lineages.

The low support found for the deep nodes in the mitogenome tree suggests that mitochondrial data alone-even complete mitochondrial genomes-might be insufficient to reliably resolve several of the deepest nodes in the Brachycephalus tree. However, in one case, we detected a clear disagreement between phylotranscriptomic and mitogenomic trees: the mitogenomic tree placed $B$. albolineatus sister to all other included species of the group (in general agreement with the mitochondrial tree of [36]), whereas the phylotranscriptomic tree suggested a sister-group relationship to B. actaeus. This cytonuclear discordance in the placement of $B$. albolineatus might reflect inter-lineage gene flow. Our phylotranscriptomic tree includes only a small subset of species of the B. pernix group but according to the available mitochondrial gene trees (e.g., [36]) all species in the group are closely related, with maximum uncorrected pairwise distances in the 16S rRNA gene of $<5.7 \%$, and $<1.4 \%$ between many closely related species [36] (Supplementary Figure S6). Brachycephalus albolineatus is closely related to B. boticario, B. fuscolineatus, and B. mirissimus based on mitochondrial data ([37]; present study), and a mitochondrial introgression from one of those species could explain the observed discordance. Alternatively, the species could have conserved a mitochondrial genome reflecting its evolutionary origins and its original nuclear genome diluted by frequent gene flow from other lineages close to B. actaeus. In amphibians, a similar situation of a divergent "ghost" mitochondrial genome not reflecting the evolutionary affinities of the nuclear genome was found for example in the salamander Salamandra salamandra longirostris from Spain [38,39]. Salamandrids have also served as a model to demonstrate pervasive hybridization among ancestral amphibian lineages [40], a phenomenon that might also affect the phylogeny of the genus Brachycephalus.

\subsection{Challenges and Perspectives for Future Taxonomic and Evolutionary Studies}

In our study, the intraspecific genetic variation found for the species with more than one sample analysed was very low. Particularly, for Brachycephalus actaeus, we included samples from different collecting points with remarkable colour variation (green, brownish, and orange, Supplementary Figure S1). Both datasets recovered B. actaeus as monophyletic with very short branches, providing further evidence for a polytypic species with substantial intra-specific colour variation. One of the phenotypes (orange) is more similar to that of other orange-colored species of the B. pernix group such as B. mirissimus. This example illustrates a new challenge to the taxonomy of this genus and may be caused by different populations of a species being subject to distinct selective pressures, translated into different frequencies of a dazzling variety of colour phenotypes. There are a few examples of similar systems in anurans, including poison-frogs of the families Dendrobatidae [12,13] and Mantellidae [41,42].

We flag as priorities for future investigation the inclusion of additional species such as $B$. didactylus in the phylotranscriptomic analysis, as well as including more specimens per species to better understand the limits of genetic and geographical variation within polytypic Brachycephalus species. It is also worth considering that several of the branches at the base of the phylogenomic tree are very short, including those that are most informative regarding the evolution of the pumpkin-toadlet phenotype, and these relationships may easily be influenced by introgression and thus be less stable than they appear in our tree. Once the crucial missing taxon (B. didactylus) has been included in the phylogenomic data set and its relationships reliably reconstructed, it will be crucial to perform introgression tests to better understand the origins of cyto-nuclear discordance and to provide a fully reliable test of the hypothesis of homoplastic evolution of this phenotype. For this purpose, 
a more in-depth characterization of the phenotypical groups is also needed. This should include objective assessments of color brightness, ideally with reflectance measurements against the background of the species' habitats, as well as quantification of the body shape differences between pumpkin-toadlets and flea-toads.

While Brachycephalus have the potential to become a promising model taxon to understand the evolution of coloration, body plan and toxicity, comprehensive analyses are currently hampered by the poor taxonomic coverage of toxin analyses. Only few species of Brachycephalus have been screened for TTX and other toxic compounds, and most importantly, not a single flea-toad species has so far been included in these screens. It is therefore important to conduct a more extensive toxin screening, both in pumpkin-toadlets and flea-toads, to understand if bright colour in this genus is linked to toxicity and/or presence of TTX. In the same context, a broad experimental assessment of their supposed unpalatability to predators and the functions of their bony plates and associated fluorescent skeleton $[11,43]$ are desirable to complement what we know about the complex evolutionary history of Brachycephalus.

\section{Materials and Methods}

\subsection{Genetic Sampling}

Our sampling includes 18 individuals from nine species representing the main clades within Brachycephalus (B. actaeus, B. albolineatus, B. auroguttatus, B. hermogenesi, B. pitanga, B. pulex, B. quiririensis, B. rotenbergae, and B. sulfuratus; Table S1; Supplementary Figure S1) and one outgroup taxon (Ischnocnema henselii, a representative for the sister genus Ischnocnema; [44]; Supplementary Figure S1). Individuals were collected in the field, euthanized by applying $5 \%$ lidocaine to the skin, and the specimens were stored in RNAlater at $-80^{\circ} \mathrm{C}$ until RNA extraction. Specimens were collected under collection permits issued by ICMBio (Instituto Chico Mendes de Conservação da Biodiversidade; SISBio \#13708-2, \#17242-5, \#49587-7, and \#59889-1) and we registered the access to genetic information on the National System for the Management of Genetic Heritage and Associated Traditional Knowledge (SISGen \#A58BC2D).

RNA was extracted from about $20-100 \mathrm{mg}$ of tissue (combined or separate skin, muscle, or liver), and the extractions were performed using a standard TRIzol protocol as specified in the Supplementary Methods. Libraries for sequencing were prepared with the Illumina TruSeq Stranded mRNA Library Prep protocol (San Diego, CA, USA). The doublebarcoded libraries were sequenced on an Illumina NextSeq instrument at the Max-Planck Institute for Evolutionary Biology in Plön, Germany, in multiple $150 \mathrm{bp}$ or $75 \mathrm{bp}$ pairedend runs (along with other samples of amphibians and reptiles not used for this study) each of which combined 10-14 samples per High-Output NextSeq kit. For species with transcriptomes of multiple individuals (B. actaeus, B. quiririensis, and B. rotenbergae) we chose to analyse each sample separately to assess the performance of our phylotranscriptomic approach in recovering species-level lineages. Reads were quality-trimmed and filtered using Trimmomatic v. 0.32 [45] with default settings, and transcriptomes were de novo assembled using Trinity v. 2.1.0 [46], following published protocols [47].

\subsection{Phylotranscriptomic Analyses}

To extract orthologous genes from the transcriptomes, we relied on the jawed-vertebrate alignment from [48] which included representative taxa of chondrichthyan and actinopterygian fishes, lungfish, coelacanth, amphibians, reptiles, birds, and mammals. This original data set consisted of a total of 100 taxa and was obtained by inferring putative orthologs from 21 reference proteomes representing most major clades of jawed vertebrates, and enriching them with genome and transcriptome data from 79 additional taxa using the software " 42 " (D. Baurain, https:/ / metacpan.org/release/Bio-MUST-Apps-FortyTwo; accessed on 27 February 2021). The software " 42 " adds sequence data to the preexisting multiple sequence alignments (MSAs) after controlling for orthology using strict three-way reciprocal best BLAST hit tests, relying on a set of reference taxa available in the MSAs (query_orgs) and as complete proteomes (ref_orgs). The software performs a first BLAST search between query_orgs and ref_orgs and 
produces a database of best hits (query_best_hits). Then, a second BLAST search uses query_orgs to search the new transcriptomes to be added (org). Eventually, the identified homologs are BLAST-searched against ref_orgs and homologs are considered orthologs if the best hit with each of the reference proteomes is among the sequences in the query_best_hit list built earlier. The orthologs identified via this process are then added to the original MSAs, followed by multiple sequence alignment and redundancy filtering.

For the present study, we used the original 100-taxa dataset of [48] and enriched it with the newly sequenced Brachycephalus and Ischnocnema transcriptomes, using a new, separate round searches and alignments with the software " 42 ". After the protein-level alignment, we searched for sequences from the newly added data (Brachycephalus and Ischnocnema) that could represent putative contamination from prokaryotes and invertebrates added during the enrichment step. Such contaminant sequences might be added due to their conserved protein motifs or because they represent highly conserved genes throughout the tree of life. Contaminants were identified as significant BLAST hits against a custom protein database, and removed from the alignment.

Subsequently, for each locus the original nucleotide sequences were retrieved from the transcriptomes using leel (D. Baurain, https:/ / metacpan.org/release/Bio-MUST-AppsFortyTwo; accessed on 27 February 2021). Because data sets derived from low coverage transcriptomes or genomes may contain erroneous sequences caused by misassembly, frameshifts due to sequencing error, or recombination, and paralogs may also remain, a thorough decontamination procedure is necessary for which we employed tree-based orthology inference methods (e.g., [49]), as follows: (1) at the transcript level, highly fragmented sequences were removed (as very short transcripts are likely to produce phylogenetic artefacts simply because of too little information) and single-gene trees were inferred using RAxML v.8 [50] under a GTR $+\Gamma$ substitution model. In-paralogs were identified based on long internal branches and removed, which represents a usual approach in phylogenomics. Sequences with very long terminal branches (in practice longer than the $99 \%$ quantile of the terminal branch length distribution) were interpreted as containing sequence errors or frameshifts and also removed. (2) Next, sequences were re-aligned with MAFFT [51], transcripts were merged with ScaFos v1.25 [52] and gene trees, as well as a concatenation tree, were newly inferred. (3) Individual taxa were removed from single-gene alignments when the exclusion significantly reduced the topological distance between the gene and concatenation trees (Robinson-Foulds distance). In this step, we set very stringent thresholds and manually checked every gene tree from which sequences were to be excluded and proceeded with the exclusion only when gene tree/concatenation tree differences could not be plausibly explained by biological processes such as incomplete lineage sorting or introgression. (4) Lastly, one additional cleaning step identical to step 2 was performed. From the obtained alignments, only those with five or more Brachycephalus samples were kept, and positions with $>75 \%$ missing data were removed. Exploratory trees calculated before these decontamination steps agreed in all relevant nodes with our final tree, suggesting that these very conservative procedure has not biased our phylogenetic results.

A maximum likelihood (ML) tree was inferred from the concatenated alignment using IQ-TREE v1.6.8 [53,54], with best-fitting substitution models and gene partitions selected with BIC in ModelFinder [55], as implemented in IQ-TREE. Branch support was assessed with 1000 pseudoreplicates of SH-like approximate likelihood ratio test (aLRT). Furthermore, to account for possible effects of incomplete lineage sorting on phylogenetic inference, we also inferred a tree from the full data set using ASTRAL-II [56], a summarytree method statistically consistent with the multispecies coalescent. Gene trees used as input for ASTRAL were inferred using RAxML under a GTR $+\Gamma$ model. Branch support of the ASTRAL tree was assessed using local posterior probabilities. 


\subsection{Mitochondrial Genome Analyses}

The trimmed RNAseq reads were also used to recover mitochondrial DNA sequences. Paired-end FASTQ files were interleaved, and duplicates removed using Tally v. 14-020 [57]. We assembled mitochondrial genomes by iterative mapping using MITObim v. 1.9.1 [58], which internally uses MIRA v.4.0.2 [59]. The assembly was done in three steps: we first used the complete mitochondrial sequence of Ischnocnema henselii (GenBank accession number: MH492733) as initial seed and the mismatch parameter was set to 30 for all samples. Iterations were run until no additional reads could be incorporated into the assemblies. We evaluated the assemblies for completeness and quality by importing the mapping output from MITObim into Geneious R11 (https: / / www.geneious.com; accessed 1 February 2021). Since it was not possible to retrieve all coding genes for some Brachycephalus samples, we selected the most complete Brachycephalus mitogenome from the first round and used it as seed to reassemble all Brachycephalus samples, setting the mismatch parameter to 10 . Finally, we used mitogenomes of each species as retrieved in the second round as seed for a third round of assembly to improve coverage and fill gaps. We did not use the published mitogenome of Brachycephalus brunneus as seed (GenBank accession KY355081) because the gene order of the available sequence does not match the gene order described in the original publication [60].

We also used mitoZ [61] to de novo assemble the mitogenome of some species and visually inspected them to confirm new gene arrangements (see results). We furthermore inspected read alignments visually to exclude assembly artefacts, and carried out some further tests to verify gene orders by designing primers spanning the tRNA WANCY region and performing PCRs tests to assess the length of the amplified fragment (Supplementary Methods).

Mitogenome annotations were performed in mitoZ [61] and the annotated contigs were loaded into Geneious R11 [62]. The two rRNAs (12S rRNA and 16S rRNA) and the 13 protein-coding genes were extracted, and the protein coding genes were checked to confirm that no indels or stop codons were present. Sequences of each gene were aligned with MAFFT [51] and aligned sequences were concatenated using SequenceMatrix v1.7.8 [63] for phylogenetic inference.

Data was partitioned by gene and by codon position when appropriate and the best partition scheme was selected using PartitionFinder 2 [64] (Table S2). A mitochondrial ML tree was inferred using RAxML v. 8.2.11 [50], with 100 ML searches and 1000 nonparametric bootstrap replicates, in the CIPRES Science Gateway (http:/ / www.phylo.org; accessed 1 February 2021). The GTR $+\Gamma$ substitution model was used for all partitions. Additionally we inferred mitochondrial trees using both ML and Bayesian Inference for all Brachycephalus species available from GenBank, to further explore hypotheses of phylogenetic relationships among flea-toads and pumpkin toadlets with maximum species coverage (Supplementary Methods; Supplementary Figure S4).

\subsection{Reconstruction of Phenotype Evolution}

Ancestral character states for body shape and colour were reconstructed using two approaches: a Bayesian Markov chain Monte Carlo approach to sample character histories from their posterior probability distribution (stochastic character mapping) [65]. For this we first transformed the phylotranscriptomic tree into an ultrametric tree using the program pyr8s within the iTaxoTools package [66], fixing the root node (Brachycephalus/Ischnocnema split) at an age of 35 million years ago based on a comprehensive anuran timetree [67]. We then used the function "make.simmap" from the R package phytools [68], performing 1000 simulations. Furthermore, we explored a parsimony-based [69] optimization as implemented in TNT v.1.5 [29], also based on the (untransformed) phylotranscriptomic tree.

For reconstruction of color phenotypes, we defined species with bright color as those that have at least some part of the body surface colored bright orange: i.e., even some pumpkin-toadlets with dorsal green or brownish color have orange on hands and feet, and/or part of the ventral surface, while orange color is not observed in any of the flea- 
toads. Body shape phenotypes were classified relying on previous classifications (e.g., [20]) of species as bufoniform (robust body and pectoral girdle, head as wide as long and short snout) vs. leptodactyliform (slender body and pectoral girdle, head longer than wide, and long snout).

Supplementary Materials: The following are available online at https://www.mdpi.com/article/10 .3390/toxins13110816/s1: Supplementary Methods (RNA extraction protocol, PCR tests including new primers design for WANCY region and mitochondrial DNA inference); Figure S1, Species sampled for this study in life. Figure S2, Species tree obtained using ASTRAL. Figure S3, Maximum likelihood tree calculated from mitogenomes. Figure S4, Maximum Likelihood mitochondrial tree for all available Brachycephalus species. Figure S5, Eletrophoresis gel showing different lengths of amplified fragments including the tRNA WANCY cluster. Figure S6, Maximum Likelihood phylogenetic inference for Brachycephalus species including mito-genomes obtained here and sequence data from GenBank. Table S1, List of samples used in the present analysis. Table S2. Best partition scheme selected for the mitogenome phylogenetic analysis. Table S3, Genbank accession numbers for species included in the mitochondrial ML and BI trees shown in Figure S4.

Author Contributions: Conceptualization, M.L.L., J.P.C.M., C.F.B.H. and M.V.; methodology, M.L.L. and S.K.; formal analysis, M.L.L., L.R., I.I.; investigation, M.L.L., L.R. and E.S.; resources, J.P.C.M., E.S., O.R.-P., M.S. and L.F.T. Writing-Original draft preparation, M.L.L., J.P.C.M. and M.V.; Writing-Review and Editing, L.R., I.I., E.S., T.H.C., O.R.-P., M.S., L.F.T. and C.F.B.H.; funding acquisition, C.F.B.H. and M.V. All authors have read and agreed to the published version of the manuscript.

Funding: Work in Brazil was supported by a grant from Coordenação de Aperfeiçoamento de Pessoal de Nivel Superior (CAPES; 88881.062205/2014-01) to MLL, CFBH, and MV. MLL was supported by the National Council for Scientific and Technological Development (CNPq; \#163546/2020-7). JPCM was supported by São Paulo Research Foundation (FAPESP \#2018/09691-0). LR was supported by the Deutsche Forschungsgemeinschaft (grant VE247/16-1-HO 3492/6-1) in the framework of the "TaxonOmics" priority program. THC thanks FAPESP (\#2015/00461-1, \#2016/871-9, \#2017/26281-7) and CNPq (\#302308/2019-9, \#301381/2020-8, \#302386/2020-3, \#300810/2021-0, \#301404/2021-6) for financial support. ORP acknowledges CAPES (\#88887.343060/2019-00) for doctoral fellowship. LFT thanks grants and fellowships from FAPESP (\#2016/25358-3; \#2019/18335-5) and CNPq (\#300896/2016-6; \#302834/20206). MS acknowledges grants from Bahia Research Foundation (FAPESB, \#APP0062/2016) and CNPq, for a research fellowship (\#304999/2015-6) and funding through a PROTAX-project (\#440615/2015-1). CFBH thanks FAPESP grant (\#2013/50741-7, \#2014/50342-8) and CNPq (\#302518/2013-4), for a research fellowship. ES was supported by a grant of the Deutscher Akademischer Austauschdienst.

Institutional Review Board Statement: Experimental procedures were performed according to the regulations specified by the Conselho Nacional de Controle de Experimentação Animal and Ministério da Ciência, Tecnologia e Inovação, Brazil and were approved by the Ethics Committee on Animal Use (CEUA) of Universidade Estadual Paulista, campus Rio Claro (CEUA-IB \# 02/2019) on 13 March 2019. Specimens were collected under collecting permits issued by the Brazilian authorities (ICMBio, SISBio \#13708-2, \#17242-5, \#49587-7, and \#59889-1).

Informed Consent Statement: Not applicable.

Data Availability Statement: The raw RNAseq reads are available at the National Center for Biotechnology Information (NCBI) Sequence Read Archive (SRA) (BioProject ID number PRJNA742912). The mitochondrial sequences were submitted to GenBank (accession numbers MZ770735 -MZ770752; Table S1). All assemblies, alignments and tree files were uploaded to Figshare under the DOI $10.6084 / \mathrm{m} 9$.figshare.14884362.

Acknowledgments: The phylotranscriptomic alignment process benefited from the constant support and assistance of Hervé Philippe to whom we are enormously grateful.

Conflicts of Interest: The authors declare no conflict of interest. The funders had no role in the design of the study; in the collection, analyses, or interpretation of data; in the writing of the manuscript, or in the decision to publish the results. 


\section{References}

1. Guilford, T.; Dawkins, M. Are warning colors handicaps? Evolution 1993, 47, 400-416. [CrossRef] [PubMed]

2. Ruxton, G.D.; Sherratt, T.N.; Speed, M.P. Avoiding Attack: The Evolutionary Ecology of Crypsis, Warning Signals and Mimicry; Oxford University Press: Oxford, UK, 2004.

3. Mappes, J.; Marples, N.; Endler, J.A. The complex business of survival by aposematism. Trends Ecol. Evol. 2005, 20, 598-603. [CrossRef] [PubMed]

4. Toledo, L.F.; Haddad, C.F.B. Colors and some morphological traits as defensive mechanisms in anurans. Int. J. Zool. $2009,910892$. [CrossRef]

5. Rojas, B.; Valkonen, J.; Nokelainen, O. Aposematism. Curr. Biol. 2015, 25, R350-R351. [CrossRef]

6. Summers, K.; Speed, M.P.; Blount, J.D.; Stuckert, A.M.M. Are aposematic signals honest? A review. J. Evol. Biol. 2015, 28, 1583-1599. [CrossRef] [PubMed]

7. Rojas, B.; Burdfield-Steel, E.; De Pasqual, C.; Gordon, S.; Hernández, L.; Mappes, J.; Nokelainen, O.; Rönkä, K.; Lindstedt, C. Multimodal aposematic signals and their emerging role in mate attraction. Front. Ecol. Evol. 2018, 6, 1-24. [CrossRef]

8. Santos, J.C.; Cannatella, D.C. Phenotypic integration emerges from aposematism and scale in poison frogs. Proc. Natl. Acad. Sci. USA 2011, 108, 6175-6180. [CrossRef]

9. Saporito, R.A.; Zuercher, R.; Roberts, M.; Kenneth, G.; Donnelly, M. A Poison Frog Oophaga pumilio. Society 2007, $2007,1006-1011$.

10. Bordignon, D.W.; Caorsi, V.Z.; Colombo, P.; Abadie, M.; Brack, I.V.; Dasoler, B.T.; Borges-Martins, M. Are the unken reflex and the aposematic colouration of red-bellied toads efficient against bird predation? PLoS ONE 2018, 13, e0193551. [CrossRef]

11. Rebouças, R.; Carollo, A.B.; Freitas, M.O.; Lambertini, C.; Dos Santos, R.M.N.; Toledo, L.F. Is the conspicuous dorsal coloration of the atlantic forest pumpkin toadlets aposematic? Salamandra 2019, 55, 39-47.

12. Hagemann, S.; Pröhl, H. Mitochondrial paraphyly in a polymorphic poison frog species (Dendrobatidae; D. pumilio). Mol. Phylogenet. Evol. 2007, 45, 740-747. [CrossRef]

13. Rodríguez, A.; Mundy, N.I.; Ibáñez, R.; Pröhl, H. Being red, blue and green: The genetic basis of coloration differences in the strawberry poison frog (Oophaga pumilio). BMC Genom. 2020, 21, 1-16. [CrossRef]

14. Rudh, A.; Qvarnström, A. Adaptive colouration in amphibians. Semin. Cell Dev. Biol. 2013, 24, 553-561. [CrossRef] [PubMed]

15. Hanifin, C.T. The chemical and evolutionary ecology of tetrodotoxin (TTX) toxicity in terrestrial vertebrates. Mar. Drugs 2010, 8 , 577-593. [CrossRef] [PubMed]

16. AmphibiaWeb. University of California: Berkeley, CA, USA. Available online: https:/ / amphibiaweb.org (accessed on 1 September 2021).

17. Bornschein, M.R.; Pie, M.R.; Teixeira, L. Conservation status of Brachycephalus toadlets (Anura: Brachycephalidae) from the Brazilian Atlantic rainforest. Diversity 2019, 11, 150. [CrossRef]

18. Clemente-Carvalho, R.B.G.; Klaczko, J.; Ivan Perez, S.; Alves, A.C.R.; Haddad, C.F.B.; Dos Reis, S.F. Molecular phylogenetic relationships and phenotypic diversity in miniaturized toadlets, genus Brachycephalus (Amphibia: Anura: Brachycephalidae). Mol. Phylogenet. Evol. 2011, 61, 79-89. [CrossRef]

19. Condez, T.H.; Haddad, C.F.B.; Zamudio, K.R. Historical biogeography and multi-trait evolution in miniature toadlets of the genus Brachycephalus (Anura: Brachycephalidae). Biol. J. Linn. Soc. 2020, 129, 664-686. [CrossRef]

20. dos Reis, S.F.; Clemente-Carvalho, R.B.G.; dos Santos, C.M.S.F.F.; Lopes, R.T.; Von Zuben, F.J.; Laborda, P.R.; Perez, S.I. Skull diversity and evolution in miniaturized amphibians, genus Brachycephalus (Anura: Brachycephalidae). Anat. Rec. 2020, $304,1-15$. [CrossRef]

21. Pires, O.R.; Sebben, A.; Schwartz, E.F.; Morales, R.A.V.; Bloch, C.; Schwartz, C.A. Further report of the occurrence of tetrodotoxin and new analogues in the Anuran family Brachycephalidae. Toxicon 2005, 45, 73-79. [CrossRef]

22. Chimetto Tonon, L.A.; Rua, C.; Crnkovic, C.M.; Bernardi, D.I.; Pires Junior, O.R.; Haddad, C.F.B.; Pedrosa, C.S.G.; Souza, L.R.Q.; Rehen, S.K.; de Azevedo, G.P.R.; et al. Microbiome associated with the tetrodotoxin-bearing anuran Brachycephalus pitanga. Toxicon 2021, 203, 139-146. [CrossRef]

23. Arcanjo, D.D.R.; Vasconcelos, A.G.; Comerma-Steffensen, S.G.; Jesus, J.R.; Silva, L.P.; Pires, O.R.; Costa-Neto, C.M.; Oliveira, E.B.; Migliolo, L.; Franco, O.L.; et al. A novel vasoactive proline-rich oligopeptide from the skin secretion of the frog Brachycephalus ephippium. PLoS ONE 2015, 10, e0145071. [CrossRef]

24. Hanken, J. Adaptation of bone growth to miniaturization of body size. Bone 1993, 7, 79-104.

25. Clemente-Carvalho, R.B.G.; Antoniazzi, M.M.; Jared, C.; Haddad, C.F.B.; Alves, A.C.R.; Rocha, H.S.; Pereira, G.R.; Oliveira, D.F.; Lopes, R.T.; dos Reis, S.F. Hyperossification in miniaturized toadlets of the genus Brachycephalus (Amphibia: Anura: Brachycephalidae): Microscopic structure and macroscopic patterns of variation. J. Morphol. 2009, 270, 1285-1295. [CrossRef]

26. Condez, T.H.; Monteiro, J.P.C.; Malagoli, L.R.; Trevine, V.C.; Schunck, F.; Garcia, P.C.A.; Haddad, C.F.B. Notes on the hyperossified pumpkin toadlets of the genus Brachycephalus (Anura: Brachycephalidae) with the Description of a New Species. Herpetologica 2021, 77, 176-194. [CrossRef]

27. Folly, M.; de Luna-Dias, C.; Miguel, I.R.; Ferreira, J.C.; Machado, A.; Tadeu Lopes, R.; Pombal, J.P. Tiny steps towards greater knowledge: An osteological review with novel data on the Atlantic Forest toadlets of the Brachycephalus ephippium species group. Acta Zool. 2021, 1-35. [CrossRef]

28. Pie, M.R.; Faircloth, B.C.; Ribeiro, L.F.; Bornschein, M.R.; Mccormack, J.E. Phylogenomics of montane frogs of the Brazilian Atlantic Forest is consistent with isolation in sky islands followed by climatic stability. Biol. J. Linn. Soc. 2018, 72-82. [CrossRef] 
29. Goloboff, P.A.; Catalano, S.A. TNT version 1.5, including a full implementation of phylogenetic morphometrics. Cladistics 2016, 32, 221-238. [CrossRef] [PubMed]

30. Irisarri, I.; Mauro, D.S.; Abascal, F.; Ohler, A.; Vences, M.; Zardoya, R. The origin of modern frogs (Neobatrachia) was accompanied by acceleration in mitochondrial and nuclear substitution rates. BMC Genom. 2012, 13, 1-19. [CrossRef] [PubMed]

31. Zhang, P.; Liang, D.; Mao, R.L.; Hillis, D.M.; Wake, D.B.; Cannatella, D.C. Efficient sequencing of anuran mtDNAs and a mitogenomic exploration of the phylogeny and evolution of frogs. Mol. Biol. Evol. 2013, 30, 1899-1915. [CrossRef] [PubMed]

32. Kurabayashi, A.; Sumida, M. Afrobatrachian mitochondrial genomes: Genome reorganization, gene rearrangement mechanisms, and evolutionary trends of duplicated and rearranged genes. BMC Genom. 2013, 14. [CrossRef]

33. Mueller, R.L.; Boore, J.L. Molecular mechanisms of extensive mitochondrial gene rearrangement in plethodontid salamanders Mol. Biol. Evol. 2005, 22, 2104-2112. [CrossRef] [PubMed]

34. San Mauro, D.; Gower, D.J.; Zardoya, R.; Wilkinson, M. A hotspot of gene order rearrangement by tandem duplication and random loss in the vertebrate mitochondrial genome. Mol. Biol. Evol. 2006, 23, 227-234. [CrossRef] [PubMed]

35. Xia, Y.; Zheng, Y.; Miura, I.; Wong, P.B.Y.; Murphy, R.W.; Zeng, X. The evolution of mitochondrial genomes in modern frogs (Neobatrachia): Nonadaptive evolution of mitochondrial genome reorganization. BMC Genom. 2014, 15, 1-15. [CrossRef] [PubMed]

36. Monteiro, J.P.C.; Condez, T.H.; Garcia, P.C.A.; Comitti, E.J.; Amaral, I.B.; Haddad, C.F.B. A new species of Brachycephalus (Anura, Brachycephalidae) from the coast of Santa Catarina State, Southern Atlantic Forest, Brazil. Zootaxa 2018, 4407, 483-505. [CrossRef]

37. Pie, M.R.; Ribeiro, L.F.; Confetti, A.E.; Nadaline, M.J.; Bornschein, M.R. A new species of Brachycephalus (Anura: Brachycephalidae) from southern Brazil. PeerJ 2018, 2018, 1-27. [CrossRef]

38. Vences, M.; Sanchez, E.; Hauswaldt, J.S.; Eikelmann, D.; Rodríguez, A.; Carranza, S.; Donaire, D.; Gehara, M.; Helfer, V.; Lötters, S.; et al. Nuclear and mitochondrial multilocus phylogeny and survey of alkaloid content in true salamanders of the genus Salamandra (Salamandridae). Mol. Phylogenet. Evol. 2014, 73, 208-216. [CrossRef] [PubMed]

39. Burgon, J.D.; Vences, M.; Steinfartz, S.; Bogaerts, S.; Bonato, L.; Donaire-Barroso, D.; Martínez-Solano, I.; Velo-Antón, G.; Vieites, D.R.; Mable, B.K.; et al. Phylogenomic inference of species and subspecies diversity in the Palearctic salamander genus Salamandra. Mol. Phylogenet. Evol. 2021, 157. [CrossRef]

40. Rancilhac, L.; Irisarri, I.; Angelini, C.; Arntzen, J.W.; Babik, W.; Bossuyt, F.; Künzel, S.; Lüddecke, T.; Pasmans, F.; Sanchez, E.; et al. Phylotranscriptomic evidence for pervasive ancient hybridization among Old World salamanders. Mol. Phylogenet. Evol. 2021, 155. [CrossRef]

41. Klonoski, K.; Bi, K.; Rosenblum, E.B. Phenotypic and genetic diversity in aposematic Malagasy poison frogs (genus Mantella). Ecol. Evol. 2019, 9, 2725-2742. [CrossRef]

42. Crottini, A.; Orozco-Terwengel, P.; Rabemananjara, F.C.E.; Susanne Hauswaldt, J.; Vences, M. Mitochondrial introgression, color pattern variation, and severe demographic bottlenecks in three species of malagasy poison frogs, genus Mantella. Genes 2019, 10, 317. [CrossRef]

43. Goutte, S.; Mason, M.J.; Christensen-Dalsgaard, J.; Montealegre-Z, F.; Chivers, B.D.; Sarria-S, F.A.; Antoniazzi, M.M.; Jared, C.; Almeida Sato, L.; Felipe Toledo, L. Evidence of auditory insensitivity to vocalization frequencies in two frogs. Sci. Rep. 2017, 7, 1-9. [CrossRef]

44. Padial, J.M.; Grant, T.; Frost, D.R. Molecular systematics of terraranas (Anura: Brachycephaloidea) with an assessment of the effects of alignment and optimality criteria. Zootaxa 2014, 3825, 1-132. [CrossRef]

45. Bolger, A.M.; Lohse, M.; Usadel, B. Trimmomatic: A flexible trimmer for Illumina sequence data. Bioinformatics 2014, 30, 2114-2120. [CrossRef] [PubMed]

46. Grabherr, M.G.; Haas, B.J.; Yassour, M.; Levin, J.Z.; Thompson, D.A.; Amit, I.; Adiconis, X.; Fan, L.; Raychowdhury, R.; Zeng, Q. Trinity: Reconstructing a full-length transcriptome without a genome from RNA-Seq data. Nat. Biotechnol. 2013, $29,644-652$. [CrossRef] [PubMed]

47. Haas, B.J.; Papanicolaou, A.; Yassour, M.; Grabherr, M.; Blood, P.D.; Bowden, J.; Couger, M.B.; Eccles, D.; Li, B.; Lieber, M.; et al. De novo transcript sequence reconstruction from RNA-seq using the Trinity platform for reference generation and analysis. Nat. Protoc. 2013, 8, 1494-1512. [CrossRef] [PubMed]

48. Irisarri, I.; Baurain, D.; Brinkmann, H.; Delsuc, F.; Sire, J.Y.; Kupfer, A.; Petersen, J.; Jarek, M.; Meyer, A.; Vences, M.; et al. Phylotranscriptomic consolidation of the jawed vertebrate timetree. Nat. Ecol. Evol. 2017, 1, 1370-1378. [CrossRef] [PubMed]

49. Yang, Y.; Smith, S.A. Orthology inference in nonmodel organisms using transcriptomes and low-coverage genomes: Improving accuracy and matrix occupancy for phylogenomics. Mol. Biol. Evol. 2014, 31, 3081-3092. [CrossRef]

50. Stamatakis, A. RAxML version 8: A tool for phylogenetic analysis and post-analysis of large phylogenies. Bioinformatics 2014, 30, 1312-1313. [CrossRef] [PubMed]

51. Katoh, K.; Standley, D.M. MAFFT multiple sequence alignment software version 7: Improvements in performance and usability. Mol. Biol. Evol. 2013, 30, 772-780. [CrossRef]

52. Roure, B.; Rodriguez-Ezpeleta, N.; Philippe, H. SCaFoS: A tool for selection, concatenation and fusion of sequences for phylogenomics. BMC Evol. Biol. 2007, 7, 1-12. [CrossRef]

53. Nguyen, L.T.; Schmidt, H.A.; Von Haeseler, A.; Minh, B.Q. IQ-TREE: A fast and effective stochastic algorithm for estimating maximum-likelihood phylogenies. Mol. Biol. Evol. 2015, 32, 268-274. [CrossRef] [PubMed] 
54. Chernomor, O.; Von Haeseler, A.; Minh, B.Q. Terrace aware data structure for phylogenomic inference from supermatrices. Syst. Biol. 2016, 65, 997-1008. [CrossRef]

55. Kalyaanamoorthy, S.; Minh, B.Q.; Wong, T.K.F.; Von Haeseler, A.; Jermiin, L.S. ModelFinder: Fast model selection for accurate phylogenetic estimates. Nat. Methods 2017, 14, 587-589. [CrossRef] [PubMed]

56. Mirarab, S.; Warnow, T. ASTRAL-II: Coalescent-based species tree estimation with many hundreds of taxa and thousands of genes. Bioinformatics 2015, 31, i44-i52. [CrossRef] [PubMed]

57. Davis, M.P.A.; Van Dongen, S.; Abreu-Goodger, C.; Bartonicek, N.; Enright, A.J. Kraken: A set of tools for quality control and analysis of high-throughput sequence data. Methods 2013, 63, 41-49. [CrossRef]

58. Hahn, C.; Bachmann, L.; Chevreux, B. Reconstructing mitochondrial genomes directly from genomic next-generation sequencing reads-A baiting and iterative mapping approach. Nucleic Acids Res. 2013, 41, e129. [CrossRef]

59. Chevreux, B.; Wetter, T.; Suhai, S. Genome sequence assembly using trace signals and additional sequence information. In Proceedings of the German Conference on Bioinformatics (GCB99), Hannover, Germany, 4-6 October 1999.

60. Pie, M.R.; Ströher, P.R.; Bornschein, M.R.; Ribeiro, L.F.; Faircloth, B.C.; McCormack, J.E. The mitochondrial genome of Brachycephalus brunneus (Anura: Brachycephalidae), with comments on the phylogenetic position of Brachycephalidae. Biochem. Syst. Ecol. 2017, 71, 26-31. [CrossRef]

61. Meng, G.; Li, Y.; Yang, C.; Liu, S. MitoZ: A toolkit for animal mitochondrial genome assembly, annotation and visualization. Nucleic Acids Res. 2019, 47, e63. [CrossRef]

62. Kearse, M.; Moir, R.; Wilson, A.; Stones-Havas, S.; Cheung, M.; Sturrock, S.; Buxton, S.; Cooper, A.; Markowitz, S.; Duran, C.; et al. Geneious Basic: An integrated and extendable desktop software platform for the organization and analysis of sequence data. Bioinformatics 2012, 28, 1647-1649. [CrossRef]

63. Vaidya, G.; Lohman, D.J.; Meier, R. SequenceMatrix: Concatenation software for the fast assembly of multigene datasets with character set and codon information. Cladistics 2011, 27, 171-180. [CrossRef]

64. Lanfear, R.; Frandsen, P.B.; Wright, A.M.; Senfeld, T.; Calcott, B. Partitionfinder 2: New methods for selecting partitioned models of evolution for molecular and morphological phylogenetic analyses. Mol. Biol. Evol. 2017, 34, 772-773. [CrossRef] [PubMed]

65. Huelsenbeck, J.P.; Nielsen, R.; Bollback, J.P. Stochastic mapping of morphological characters. Syst. Biol. 2003, 52, 131-158. [CrossRef] [PubMed]

66. Vences, M.; Miralles, A.; Brouillet, S.; Ducasse, J.; Fedosov, A.; Kharchev, V.; Kostadinov, I.; Kumari, S.; Patmanidis, S.; Scherz, M.D.; et al. iTaxoTools 0.1: Kickstarting a specimen-based software toolkit for taxonomists. Megataxa 2021, 6, 77-92. [CrossRef]

67. Feng, Y.J.; Blackburn, D.C.; Liang, D.; Hillis, D.M.; Wake, D.B.; Cannatella, D.C.; Zhang, P. Phylogenomics reveals rapid, simultaneous diversification of three major clades of Gondwanan frogs at the Cretaceous-Paleogene boundary. Proc. Natl. Acad. Sci. USA 2017, 114, E5864-E5870. [CrossRef]

68. Revell, L.J. phytools: An R package for phylogenetic comparative biology (and other things). Methods Ecol. Evol. 2012, 3, 217-223. [CrossRef]

69. Fitch, W.M. Toward defining the course of evolution: Minimum change for a specific tree topology. Syst. Zool. 1971, $20,406-416$. [CrossRef] 